\title{
PERCEPÇÃO DA QUALIDADE EM SERVIÇOS CONTÁBEIS: ESTUDO DE CASO EM UM ESCRITÓRIO CONTÁBIL EM FOZ DO IGUAÇU/PR ${ }^{1}$
}

\author{
PERPEPTIONS QUALITY IN ACCOUNTING SERVICES: A CASE STUDY IN AN ACCOUNTING \\ OFFICE IN FOZ DO IGUAÇU/PR
}

\author{
Aline Ribas Maciel ${ }^{2}$ \\ Bacharel em Ciências Contábeis pela Universidade Estadual do Oeste do Paraná \\ aliine rm@hotmail.com \\ Vinicius Abilio Martins \\ Doutorando em Contabilidade pela Universidade Federal de Santa Catarina \\ Professor da Universidade Estadual do Oeste do Paraná \\ viniciusabilio@gmail.com
}

\section{RESUMO}

Objetivo: O objetivo deste estudo é avaliar a qualidade percebida no serviço prestado em um escritório contábil localizado em Foz do Iguaçu PR, por meio da aplicação da Escala Servqual.

Fundamento: A necessidade de satisfação do cliente em relação à qualidade do serviço oferecido pelos escritórios de contabilidade e a superação do que é percebido com relação ao esperado, podem ser um ponto chave da intenção comportamental e da fidelidade do cliente, diminuindo assim a pressão exercida pela concorrência. Para mensurar a qualidade esperada e percebida, pode-se utilizar da Escala Servqual.

Método: Pesquisa descritiva, de natureza quantitativa, desenvolvido sob a forma de levantamento por questionários com a Escala Servqual em estudo de caso. A população desta pesquisa foi a clientela de um escritório de contabilidade localizado na cidade de Foz do Iguaçu PR. Para a análise de dados, foram utilizadas estatísticas descritivas, coeficiente de correlação, diferença das médias e Teste T.

Resultados: Observou-se que as médias gerais para as dimensões foram positivas, apesar de algumas das variáveis apresentarem GAPs negativos. Os gaps negativos foram, justamente, as questões mais características do serviço contábil, em que se deve haver um maior zelo por parte do gestor, quanto ao cumprimento dos prazos acertados, registros atualizados e sem erros, precisão ao informar o início e conclusão de um serviço e atendimento imediato.

Contribuições: Além de identificar as dimensões que geram expectativa e satisfação na clientela do setor de serviços contábeis, a possibilidade de identificação de pontos de preocupação e melhoria que auxiliem a gestão da qualidade do setor em análise.

Palavras-Chave: Gestão da Qualidade; Qualidade dos Serviços; Serviço Contábil; SERVQUAL.

\footnotetext{
${ }_{1}$ Artigo recebido em: 27/09/2017. Revisado por pares em: 30/10/2017. Reformulado em: 16/11/2017. Recomendado para publicação em: 13/12/2017 por Luiz Felipe de Araújo Pontes Girão (Editor Geral). Publicado em: 14/02/2017. Organização responsável pelo periódico: UFPB.

2 Endereço: R. Universitária, 2069 - Universitário, Cascavel - PR, 85819-110

DOI: http://dx.doi.org/10.18405/recfin20180206
} 


\section{ABSTRACT}

Objective: The objective of this study is to evaluate the quality perceived by the service rendered from an accounting office, located in Foz do Iguaçu PR, through the application of the Servqual scale. Background: The need for customer satisfaction in relation to the quality of service offered by the accounting offices and the overcoming of what is perceived in relation to the expected can be a key point of behavioral intentions and the loyalty of the client, thus reducing the pressure exerted by the client. competition. To measure the expected and perceived quality, one can use the Servqual Scale. Method: Descriptive research, of quantitative nature, developed in the form of a questionnaire survey with the Servqual Scale in a case study. The population of this research is the clientele of an accounting office, located in the city of Foz do Iguaçu. For the analysis of data, we used descriptive statistics, correlation coefficient, difference of means, Test $\mathrm{T}$.

Results: It was observed that the general averages for the dimensions were positive, although some of the variables presented negative GAPs. Negative gaps are precisely the issues that are most characteristic of accounting service, where the manager must be more zealous, being related to the fulfillment of promised deadlines, updated and error-free records, accuracy in reporting the start and completion of a service and immediate care.

Contributions: In addition to identifying the dimensions that generate expectation and satisfaction in the clientele in the accounting services sector, the possibility of identifying points of concern and improvement that help in the quality management of the sector under analysis.

Keywords: Quality Management; Quality of Services; Accounting Service; SERVQUAL.

\section{INTRODUÇÃO}

As organizações, independentemente de sua área de atuação, inserem-se em ambientes cada vez mais competitivos e dinâmicos (Martins, 2015). A concorrência entre as empresas é um dos fatores que vêm trazendo grande preocupação para os gestores. A queda no mercado acarreta diversos problemas para as empresas, podendo levá-las à falência. Desta forma, as organizações devem se preocupar com a sua participação no mercado, para que permaneçam competitivas. Dentre as organizações em questão, encontram-se os escritórios prestadores de serviços contábeis, ou escritórios contábeis.

A contabilidade está inserida no ramo de serviços, "vendendo" seus serviços contábeis e fiscais necessários às pessoas físicas e jurídicas. O serviço de contabilidade exige não só competências e conhecimentos profissionais, mas também inovação na transformação de negócios, fornecendo valor a seus clientes para enfrentar o mercado competitivo (Lee, Peng \& Fan, 2016). Uma das funções do contador é produzir informações úteis e relevantes aos usuários da contabilidade para auxílio na tomada de decisão (Comitê de Pronunciamentos Contábeis, CPC 00).

O setor contábil auxilia a gestão das empresas, tanto pequenas como grandes, pois além de manter a documentação de todas as operações para comprovar os registros contábeis e fiscais, trata da coleta dos dados, apresentação e interpretação dos fatos econômicos, possibilitando que as informações geradas, sejam tomadas como ponto de referência para as decisões da administração e possibilite a apresentação de sugestões que auxiliem o desenvolvimento de seus clientes. O contador pode fornecer informações de qualidade ao empresário sobre todas as áreas e departamentos, ajudando-o a melhorar o patrimônio e o modo de administrar a sua empresa (Madruga, Colossi \& Biazus, 2016, Comitê de Pronunciamentos Contábeis, CPC 00).

Este cenário desperta nas empresas prestadoras de serviços contábeis, a necessidade de satisfação do cliente em relação ao serviço que lhe é oferecido. Diante disto, cabe aos escritórios contábeis buscar alternativas diferenciadas para melhorarem, ao máximo, os serviços prestados aos seus 
clientes. A qualidade do serviço prestado pode ter um efeito direto ou indireto nas intenções comportamentais ou na fidelidade do cliente (Chang \& Yeh, 2017).

A capacidade para entender as necessidades do cliente, a confiabilidade, a boa comunicação, a fácil utilização, a credibilidade, a competência, a segurança, a agilidade na resposta são alguns dos aspectos que clientes buscam em seus prestadores de serviços. E neste caso, os escritórios de contabilidade estão inclusos (Martins \& Laugeni, 2001, Souza, Valter \& Bach, 2013).

Apesar de ser uma tarefa difícil, satisfazer os clientes pode trazer uma série de benefícios importantes para as empresas prestadoras de serviços, especialmente para as prestadoras de serviços contábeis, e dessa forma, fidelizarem seus clientes. Neste sentido, emerge a seguinte questão de pesquisa: como a qualidade de um serviço é percebida pelos clientes de um escritório de serviços contábeis?

Para responder a este questionamento, esta pesquisa tem como objetivo avaliar a qualidade percebida pelo serviço prestado de um escritório contábil, localizado em Foz do Iguaçu PR, por meio da aplicação da escala Servqual.

Além de identificar as dimensões que geram expectativa, satisfação e pontos objetos de melhoria que auxiliem na gestão da qualidade de serviços contábeis, esta pesquisa se justifica por também contribuir para uma melhor compreensão a respeito do campo prático e teórico que trata sobre a prestação de serviços contábeis.

De forma prática, se justifica por permitir aos escritórios de contabilidade, por meios científicos, identificar qual a percepção dos seus clientes sobre a qualidade do serviço prestados e determinar quais pontos podem ser melhorados dentro da empresa. Tais melhorias podem culminar em uma melhor satisfação de sua clientela. No campo teórico, a contribuição para identificar construtos significativos com relação à percepção dos clientes.

Tomando por base a literatura existente no Brasil, não foram encontrados trabalhos que abordem a mensuração da qualidade percebida na prestação de serviços contábeis por meio da Escala Servqual. Foram identificados trabalhos nas áreas de instituições de ensino superior, área da saúde, pousadas, turismo, setor hoteleiro, farmacêutico, alimentício, bancário, serviços de comércio, comércio de livros, serviços industriais e manufatura, serviços de biblioteca, franquias, incubadoras de empresas, feiras livres, setor de softwares, redes sociais on line, setor público, setor educacional e ensino de línguas, setor de construção habitacional, curtumes, serviços de TI e serviços automotivos.

\section{REFERENCIAL TEÓRICO}

\subsection{Gestão de Serviços}

A partir do século $X X$, o setor de serviços tem ganhado grande importância e destaque na economia brasileira, sendo responsáveis pela maior parcela do PIB, inclusive, em nível mundial (Caon \& Correa, 2008, Souza, 2010). No Brasil, o setor de serviços é responsável por 73\% do PIB (IBGE, 2017) e também o setor que mais emprega, responsável por $67,7 \%$ dos empregos formais ao final de 2016 (IBGE, 2017).

Segundo a NBR ISO 9000/2000 (ABNT 2000), serviços são resultados de uma ou mais atividades desempenhadas pela interface entre fornecedor de serviços e cliente e geralmente tem característica intangível. Sendo assim, a prestação de serviços pode envolver vários fatores, dentro deles uma atividade realizada em um produto tangível fornecido pelo cliente, a criação de um ambiente confortável e agradável ou a entrega de um produto intangível.

Para Mochon e Troster (1999), serviços são aquelas atividades para satisfazer as necessidades humanas, sem criar objetos materiais. Wilson, Zeithaml, Bitner e Gremle (2012) apontam que o principal objetivo dos prestadores de serviços é o mesmo de qualquer outro setor empresarial, ou seja, 
ofertar seu serviço para satisfazer as necessidades e expectativas desejadas de seu consumidor, de modo a garantir sua própria sobrevivência no mercado econômico.

Para Martins e Laugeni (2001) e Souza, Valter e Bach (2013), os parâmetros dos serviços envolvem: a capacidade para entender as necessidades do cliente, a confiabilidade, a boa comunicação, a fácil utilização, a credibilidade, a competência, a segurança, a agilidade na resposta e seus aspectos visíveis.

A capacidade para entender as necessidades está relacionada com a finalidade para satisfazer seu cliente; a confiabilidade é o grau de confiança entre o cliente e o prestador de serviço; a fácil utilização significa o serviço ser simples e acessível; a credibilidade deve ser um atributo do serviço e também está relacionado à confiabilidade. Por sua vez, a confiabilidade significa a aptidão para cumprir o serviço combinado; a segurança em relação à prestação de serviço é o ato de segurar o cliente e a agilidade na resposta está ligada ao cumprimento de prazos, pois quando o cliente contrata um serviço, na maioria dos casos o mesmo tem um prazo para ser cumprido.

\subsection{Características e Qualidade dos Serviços}

Os serviços se caracterizam por serem intangíveis, inseparáveis, heterogêneos e simultâneos. A intangibilidade refere-se a não ser produto físico, ou seja, não é possível tocá-lo, vê-lo, prová-lo, senti-lo ou cheirá-lo. A inseparabilidade refere-se a não poder ser estocado. A heterogeneidade refere-se que cada serviço é distinto a cada vez que é executado, mesmo que por pequenas variações. A simultaneidade refere-se ao fato do consumo e a prestação do serviço ocorrerem ao mesmo tempo (Las Casas, 1994).

Como o envolvimento e a ligação entre o consumidor e o prestador de serviço são subjetivos (Martins \& Laugeni, 2001, Souza, Walter \& Bach, 2013), a qualidade é uma das variáveis de decisão mais importantes dos usuários para escolher entre bens e serviços em mercados competitivos. Desta forma, a qualidade do serviço é um fator estratégico para colocar as empresas em uma posição competitiva favorável (Fragoso \& Espinosa, 2017).

A qualidade em uma organização de serviços é uma medida do alcance a que o serviço prestado atende às expectativas do cliente (Yousapronpaiboon, 2014). A qualidade dos serviços pode ser definida como a capacidade de uma experiência satisfazer uma necessidade, resolver um problema ou fornecer algum benefício (Albrecht, 1992), podendo variar entre os consumidores (Las Casas, 1994), mas devendo considerar a visão do cliente (Grönroos, 1995), haja vista que é a sua percepção que interessa. Téboul (1999) aponta que a qualidade de um serviço é julgada pelo processo do atendimento e por seus resultados.

Assim, a qualidade pode ser entendida como a totalidade das características de um produto ou serviço sobre o qual a sua capacidade de satisfazer certas necessidades é sustentada (Evans \& Lindsay, 2005, Fragoso \& Espinosa, 2017).

A qualidade percebida pode ser entendida como uma lacuna entre as expectativas dos clientes e sua percepção do serviço. A busca pela qualidade é uma condição imposta tanto pelo mercado atual, quanto pelos seus usuários. Neste caso, a maior contribuição da qualidade é a busca em preencher a lacuna que existe entre os aspectos técnicos dos serviços e a capacidade de atender bem aos clientes, tornando-o, assim, não só objeto estratégico a ser perseguido, como fonte de vantagem competitiva (Slack et al., 2002). Além disso, a qualidade do serviço pode ter um efeito direto ou indireto nas intenções comportamentais ou fidelidade dos clientes (Chang \& Yeh, 2017), sendo este também uma das preocupações das grandes empresas (Jeremias Junior \& Martins, 2017).

Quando uma empresa oferece qualidade em seus serviços que, atenda ou exceda as expectativas dos clientes, o resultado possível será a satisfação e lealdade do cliente (Izodo \& Ogba, 2015). Para Schiffman et al. (2012) e Izodo e Ogba (2015), a qualidade do serviço é um determinante se o 
consumidor permanece com a empresa (lealdade) ou deixa a organização em favor dos concorrentes. Assim, o sucesso a longo prazo de uma organização de serviços é essencialmente determinado pela sua capacidade de expandir e manter uma base de clientes grande e leal por meio da qualidade do serviço que atenda ou exceda as expectativas dos clientes (Izodo \& Ogba, 2015).

Zeithaml, Parasuraman e Berry (1990) atribuem à qualidade dos serviços, o resultado entre as expectativas geradas e as percepções obtidas dos clientes sobre o que lhe foi oferecido, deste modo, os clientes experimentam vários níveis de satisfação após cada serviço e avaliam se suas expectativas, quanto ao serviço tomado, foram superadas.

As definições de qualidade mais associadas aos produtos físicos, são muitas vezes insuficientes para que se compreenda a qualidade de serviços que não são físicos. A dificuldade na avaliação da qualidade de serviços se deve às características únicas que os identificam: intangibilidade, heterogeneidade e inseparabilidade (Parasuraman, Zeithaml \& Berry, 1985, 1988, Faião, Maranhão \& Torres, 2013).

A intangibilidade é a principal característica que dificulta a percepção e avaliação da qualidade dos serviços pelo cliente, porque grande parte dos serviços não podem ser contados, medidos, testados, inventariados e verificados antes do acordo comercial entre as partes, para garantir a sua qualidade (Parasuraman, Zeithaml \& Berry, 1985, Faião, Maranhão \& Torres, 2013).

Em seguida, vem a heterogeneidade dos serviços, especialmente aqueles com várias tarefas, em que o desempenho pode variar de empresa para empresa, cliente para cliente e dia para dia. (Parasuraman, Zeithaml \& Berry, 1985-1988, Faião, Maranhão \& Torres, 2013). E, por último, a inseparabilidade dos serviços em que a produção e o consumo não estão separados. Em virtude dessas características, as empresas têm maior dificuldade em compreender como os clientes percebem seus serviços e a qualidade de seus serviços (Parasuraman, Zeithaml \& Berry, 1985, 1988, Faião, Maranhão \& Torres, 2013).

A qualidade de serviços e a satisfação do cliente são dois fatores que estão ligados um ao outro. Fitzsimmons e Fitzsimmons (2000) definem que a satisfação do cliente com um serviço depende do nível de atendimento e da expectativa do cliente quanto ao serviço prestado.

Segundo Grönroos (1995), os usuários do serviço escolhem seus prestadores, fazendo uma comparação entre as percepções que os mesmos têm sobre o que lhes foi oferecido e o que desejava. Sendo assim, apenas quando o prestador de serviços entende o processo de percepção e avaliação dos clientes, é que se torna possível influenciá-los para seguir na direção desejada. Além disso, a qualidade do serviço é tida como um determinante importante da satisfação do cliente, o que, por sua vez, influencia a fidelidade dos clientes (Izogo \& Ogba, 2015).

Avaliar o desempenho, inclusive de serviços, trata-se do exercício de análise e julgamento sobre a natureza, sobre o mundo e as ações humanas, a base para a apreciação de um fato, de uma ideia, de um objetivo ou de um resultado (Rosa et al., 2014). Não basta somente entender a importância de prestar serviços de qualidade, é necessário que a haja um processo contínuo de monitoramento quanto às percepções dos clientes sobre a qualidade do serviço, identificação das causas das divergências encontradas e adoção de práticas adequadas para a melhoria da qualidade do serviço prestado (Fadel \& Régis Filho, 2009). O modelo conceitual do serviço de qualidade acredita que há uma diferença entre a qualidade do serviço percebida e esperada pelos clientes (Lee, Peng \& Fan, 2016).

Assim, a qualidade dos serviços, inserido no âmbito da gestão dos serviços, pauta-se na satisfação não apenas de uma necessidade por parte do cliente, mas de atingir e superar uma expectativa, a partir da percepção deste cliente.

\subsection{Prestação de Serviços Contábeis}


O serviço de contabilidade exige não só competências e conhecimentos profissionais, mas também inovação na transformação de negócios, fornecendo valor a seus clientes para enfrentar o mercado competitivo (Lee, Peng \& Fan, 2016).

As empresas que prestam serviços contábeis precisam sempre buscar satisfazer as necessidades dos seus clientes, procurando sempre executar seus serviços com qualidade. Espera-se do profissional contábil que ele esteja constantemente se atualizando, buscando novos conhecimentos para melhorar a qualidade do serviço prestado e aumentar a oferta dos serviços. Sobre isto, Thomé (2001) e Carvalho e Tomaz (2010) concluíram que as empresas que prestam serviços contábeis precisam ter uma visão holística, pois ofertam seus serviços para pessoas físicas e jurídicas, que atuam em todos os ramos da atividade econômica.

Segundo Thomé (2001) e Carvalho e Tomaz (2010), o contador trabalha com assuntos contábeis, tributários, fiscais, legislação comercial, trabalhistas e previdenciários, e nestas áreas, a legislação sofre alterações constantemente. Alterações essas que, para serem devidamente entendidas e aplicadas, necessitam que o profissional acompanhe a legislação atentamente.

Para Augusto (2006) e Carvalho e Tomaz (2010), o serviço contábil deve ser visto pelo empresário como sendo de boa qualidade e, para isso, deve-se seguir alguns quesitos básicos: atender as normas fiscais, estar de acordo com os princípios contábeis, cumprir os prazos estabelecidos pelos fiscos federal, municipal e estadual, realizar os serviços em tempo hábil e com segurança e manter controle no âmbito gerencial das empresas.

Lopes e Martins (2007) e Carvalho e Tomaz (2010), afirmam que a contabilidade deve fornecer informações a todos os tipos de usuários. Para se obter qualidade nos serviços prestados pelo profissional contábil, é necessário que o contador domine o que está fazendo, pois a qualidade no serviço contábil prestado, depende, diretamente, do conhecimento e do comprometimento em exercer a profissão.

Diante do exposto, a necessidade de satisfação do cliente em relação a qualidade do serviço oferecido pelos escritórios de contabilidade e a superação do que é percebido com relação ao esperado, podem ser um ponto chave das intenções comportamentais e da fidelidade do cliente, diminuindo assim, a pressão exercida pela concorrência

\section{METODOLOGIA DA PESQUISA}

\subsection{Delineamento da Pesquisa}

Pesquisa descritiva, de natureza quantitativa, desenvolvida sob a forma de levantamento por questionários em estudo de caso com o objetivo de avaliar a qualidade percebida pelo serviço prestado de um escritório contábil localizado em Foz do Iguaçu - PR, por meio da aplicação da escala Servqual.

A população desta pesquisa foi composta por 250 (duzentos e cinquenta) clientes, dos quais 100 (cem) confirmaram o recebimento dos questionários e 62 (sessenta e dois) responderam, sendo este último número, o tamanho da amostra. As respostas foram recebidas pessoalmente ou por meio de e-mail cuja divulgação do nome e de outros detalhes que possibilitassem sua identificação não foi autorizada.

Para as respostas ao questionário, foi utilizado escala Likert de 7 pontos, sendo a 1 - Discordo Totalmente até 7 - Concordo Totalmente. A Escala Servqual foi dividida em dois questionários, cada um contendo 22 (vinte e duas) afirmativas referentes a expectativa e percepção da qualidade do serviço prestado pelas organizações. Por intermédio do primeiro questionário, o respondente demonstra suas expectativas em relação ao serviço a ser usado. No segundo questionário, ele manifesta suas reais percepções acerca do serviço propriamente consumido. 
Os questionários aplicados englobam cinco constructos, cada um com um número determinado de afirmativas. Ao considerar, para a coleta de dados, a escala entre 1 a 7 , individualmente, as declarações poderão variar de uma pontuação mínima de 62 (sessenta e dois) pontos (número de questionários respondidos $\times$ menor pontuação possível $=62 \times 1=62$ pontos) até uma pontuação máxima de 434 (quatrocentos e trinta e quatro) pontos (respostas obtidas x pontuação máxima possível $=62 \times 7=434$ pontos $)$.

Para a análise de dados, foram utilizados: estatísticas descritivas, coeficiente de correlação, diferença das médias e o Teste T. Conforme conceitua Mann (2006, p. 3), “a estatística descritiva consiste em métodos para se organizar, exibir e descrever dados utilizando tabelas, gráficos e medidas resumidas". Neste trabalho foram calculadas medidas de dispersão da amostra, tais como o desvio-padrão $\left(\sigma \_\bar{x}\right)$ e valores mínimos e máximos, e medidas de tendência central, como a média aritmética $(\bar{x})$. Para o cálculo dessas medidas, foi utilizado o software IBM SPSS Statistics versão 22 (versão disponibilizada pela instituição de ensino), que oferece os instrumentos necessários para o cálculo e a análise dos dados.

Após realizado o teste de Normalidade dos dados, por meio do teste Kolmogorov-Smirnov, não foi identificado distribuição normal destes. Tal quesito se faz necessário para identificação dos testes seguintes a serem utilizados. O teste $\mathrm{T}$ é usado quando se têm duas condições e se quer saber se, a diferença entre as médias é significante ou não, para uma amostra com número menor de observações (Dancey \& Reidy, 2006). Os coeficientes de correlação de Spearman e Kendall, utilizados neste trabalho, são medidas de dependência estatística entre duas variáveis que pode indicar o quão bem uma relação pode ser descrita, quando não se apresentam dados com distribuição normal e, no caso de Kendall, se apresentem muitos dados repetidos (Field, 2009).

\subsection{Instrumento de Intervenção - Escala Servqual}

A Escala Servqual é uma ferramenta para medir a qualidade do serviço prestado de qualquer organização (Parasuraman, Zeithaml \& Berry, 1985). É uma escala universal, pois pode ser utilizada em qualquer organização de serviços. Serve para descobrir e encontrar quais são as áreas de forças e de fracassos dentro de uma empresa (Tan \& Pawitra, 2001), permitindo identificar todos os problemas que aparecem no processo de fornecimento (Wolniak \& Skotnicka-Zasadzien, 2012, Pradela, 2015).

A Escala Servqual tem sido utilizada nos estudos de qualidade de serviço, o que demonstra sua importância. A mesma surgiu por meio de estudos para medir a qualidade de serviço, onde Parasuraman, Zeithaml e Berry (1985) e Parasuraman, Zeithaml e Berry (1988) se basearam na comparação entre a percepção sobre o serviço recebido e o serviço esperado pelo usuário. As cinco dimensões do modelo são confiabilidade, presteza, segurança (ou garantias), empatia e aspectos tangíveis que agrupam os problemas da qualidade em lacunas, chamados "gaps" (Parasuraman, Zeithaml \& Berry 1985,1988, Pradela; 2015).

A dimensão da Confiabilidade consiste em executar o trabalho correto desde a primeira vez, cumprindo os prazos combinados, interesse na resolução dos problemas; Presteza consiste na representação da boa vontade por parte do prestador do serviço em ajudar, resolver o problema do cliente e promover os serviços; Segurança se relaciona à ausência do perigo, risco ou dúvida, em relação ao serviço, sendo de aspectos físicos, financeiros ou de confidencialidade; Empatia está relacionada à atenção individualizada e cuidadosa que as empresas oferecem aos seus clientes e Tangibilidade, está diretamente ligado à aparência física e estrutural das instalações, equipamentos, pessoal e material de comunicação (Parasuraman, Zeithaml \& Berry 1985). 
A diferença entre serviço percebido e serviço esperado foi denominado lacuna (gap, em inglês). Sendo assim, Parasuraman, Zeithaml e Berry (1985, 1988), concluíram, como principal resultado de suas pesquisas, que os clientes utilizam os mesmos critérios para chegar a um julgamento sobre a qualidade do serviço prestado, independentemente do tipo de serviço considerado.

A Escala Servqual, além de mensurar a percepção dos clientes em relação à qualidade do serviço prestado, verifica quais dimensões dentro da empresa podem ser melhoradas (Johnston, 1995; Souza, Walter \& Bach, 2013).

\section{APRESENTAÇÃO E ANÁLISE DOS RESULTADOS}

Dentre os resultados descritivos nesta pesquisa, pode-se identificar que, quanto ao ramo de atividade das empresas entrevistadas, a maioria pertence a ramos de atividade ligados ao comércio e serviços, representando 36\%. Empresas do ramo comercial foram compostas por $29 \%$ dos respondentes. Empresas de prestação de serviço corresponderam a 33\% e do segmento industrial corresponderam a $2 \%$ dos respondentes.

Além destas características, o número de funcionários que estas empresas possuem são: de 0 a 15 , representam $72 \%$, predominantemente por empresas do ramo comercial; com 16 a 30 funcionários, representam $2 \%$ e a partir de 31 funcionários, $26 \%$ das respostas, em sua maioria do ramo industrial.

Quanto ao tempo de cliente no escritório de contabilidade, identificou-se que $45 \%$ são clientes, no máximo, há 4 anos; de 5 a 10 anos, corresponde à 23\%, são clientes da empresa há mais 10 anos e correspondem à $32 \%$. Esta informação é importante para se identificar quais tipos de clientes o escritório, objeto desta pesquisa, atende, a fim de contextualizar as respostas e promover análises melhores.

Após identificar as características gerais das empresas respondentes, foram levantadas as informações a respeito do desempenho esperado por estes clientes, por parte do escritório de contabilidade objeto deste estudo.

A Tabela 1, mostra a estatística descritiva para o desempenho esperado, mantida a ordem original das dimensões propostas por Parasuraman, Zeithaml e Berry $(1985,1988)$ : 
Tabela 1 - Estatísticas descritivas para as expectativas dos respondentes

\begin{tabular}{ccccccc}
\hline Questão & Mínimo & Máximo & Somatório & Média por dimensão & Média & Desvio Padrão \\
\hline TangE1 & 1 & 7 & 370 & & 5,9677 & 1,4482 \\
TangE2 & 1 & 7 & 312 & 335 & 5,0322 & 1,5782 \\
TangE3 & 2 & 7 & 324 & & 5,2258 & 1,7687 \\
TangE4 & 1 & 7 & 334 & 5,3871 & 1,5718 \\
\hline ConfE5 & 1 & 7 & 363 & 5,8548 & 1,5560 \\
ConfE6 & 1 & 7 & 404 & 392,6 & 6,5161 & 1,1270 \\
ConfE7 & 4 & 7 & 395 & 6,3710 & 1,1341 \\
ConfE8 & 1 & 7 & 400 & 6,4516 & 1,2103 \\
ConfE9 & 1 & 7 & 401 & 6,4677 & 1,2895 \\
\hline RespE10 & 1 & 7 & 407 & 6,5645 & 1,2495 \\
RespE11 & 1 & 7 & 389 & 378,5 & 6,2742 & 1,2696 \\
RespE12 & 1 & 7 & 397 & & 6,4032 & 1,2862 \\
RespE13 & 4 & 7 & 321 & 5,1774 & 1,1945 \\
\hline SegE14 & 1 & 7 & 396 & 6,3871 & 1,2976 \\
SegE15 & 1 & 7 & 387 & 390,25 & 6,2419 & 1,3632 \\
SegE16 & 4 & 7 & 397 & 6,4032 & 0,9314 \\
SegE17 & 4 & 7 & 381 & 6,1452 & 0,9892 \\
\hline EmpE18 & 4 & 7 & 367 & 5,9194 & 1,2186 \\
EmpE19 & 1 & 7 & 345 & 357 & 5,5645 & 1,4442 \\
EmpE20 & 1 & 7 & 317 & 5,1129 & 2,0333 \\
EmpE21 & 4 & 7 & 378 & 6,0968 & 1,0034 \\
EmpE22 & 1 & 7 & 378 & 6,0968 & 1,4224 \\
\hline & & & Fonte: dados da pesquisa. & &
\end{tabular}

Por meio da Tabela 1, pode-se notar que as maiores expectativas dos clientes encontram-se concentradas na "disposição dos funcionários em ajudar - Responsividade", com a maior expectativa - 6,5645, "Confiabilidade - execução trabalho correto" e "Confiabilidade - cumprindo os prazos combinados e interesse na resolução dos problemas", sendo 6,5161 e 6,4677 respectivamente. A menor expectativa encontrada foi a Tangibilidade, que tem relação com as instalações físicas, com média de 5,0323 .

As afirmativas que ocuparam maior posição em relação à soma dos pontos dados pelos respondentes referem-se ao conceito "qualidade de serviço contábil". Assim, pode-se inferir que, além dos aspectos tangíveis, os aspectos qualidade do serviço - cumprimento de prazos combinados, interesse na resolução dos problemas, disposição dos funcionários em ajudar - característicos do serviço contábil, são muito importantes, do ponto de vista do cliente, usuário do serviço. Mesmo a menor expectativa, sendo na dimensão Tangibilidade, observou-se que nenhuma delas foi inferior a 5, todos os aspectos são de grande relevância para o cliente.

A Tabela 2, apresenta as estatísticas descritivas para as percepções dos respondentes: 
Tabela 2 - Estatísticas descritivas para as percepções dos respondentes

\begin{tabular}{ccccccc}
\hline Questão & Mínimo & Máximo & Somatório & Média por dimensão & Média & Desvio Padrão \\
\hline TangP1 & 4 & 7 & 378 & & 6,0968 & 1,0970 \\
TangP2 & 4 & 7 & 409 & 401,75 & 6,5968 & 0,7987 \\
TangP3 & 4 & 7 & 409 & & 6,5968 & 0,7987 \\
TangP4 & 4 & 7 & 411 & 6,6290 & 0,7732 \\
\hline ConfP5 & 1 & 7 & 392 & & 6,3226 & 1,0830 \\
ConfP6 & 4 & 7 & 409 & 397,40 & 6,5968 & 0,7346 \\
ConfP7 & 4 & 7 & 408 & & 6,5806 & 0,8005 \\
ConfP8 & 4 & 7 & 395 & & 6,3710 & 0,9449 \\
ConfP9 & 1 & 7 & 383 & 6,1774 & 1,1383 \\
\hline RespP10 & 3 & 7 & 392 & & 6,3226 & 1,0366 \\
RespP11 & 4 & 7 & 385 & 388,25 & 6,2097 & 0,8709 \\
RespP12 & 4 & 7 & 411 & 6,6290 & 0,7941 \\
RespP13 & 4 & 7 & 365 & & 5,8871 & 0,9935 \\
\hline SegP14 & 4 & 7 & 407 & & 6,5645 & 0,8020 \\
SegP15 & 4 & 7 & 398 & 6,4194 & 0,9329 \\
SegP16 & 4 & 7 & 416 & & 6,7097 & 0,6625 \\
SegP17 & 4 & 7 & 394 & 6,3548 & 0,9250 \\
\hline EmpP18 & 4 & 7 & 396 & & 6,3871 & 0,9295 \\
EmpP19 & 4 & 7 & 397 & 394,8 & 6,4032 & 0,9488 \\
EmpP20 & 4 & 7 & 389 & & 6,4194 & 0,9438 \\
EmpP21 & 4 & 7 & 398 & 6,3548 & 1,1321 \\
EmpP22 & 1 & 7 & 394 & & & 0,9329 \\
\hline
\end{tabular}

Fonte: dados da pesquisa.

Por meio da Tabela 2, pode-se notar que o maior desempenho percebido pelos clientes, encontra-se na Segurança (6,7097), em SegP16. Além disso, identifica-se que apenas Responsividade RespP13, encontra-se com valores abaixo de 6, com 5,8871. Isso denota que, em média, para praticamente todas as respostas, o escritório de contabilidade atende às expectativas.

A Figura 1 apresenta o comparativo da média das dimensões referentes às expectativas e percepções:

Figura 1 - Comparativo da Média das dimensões 'Expectativas x Percepção'.

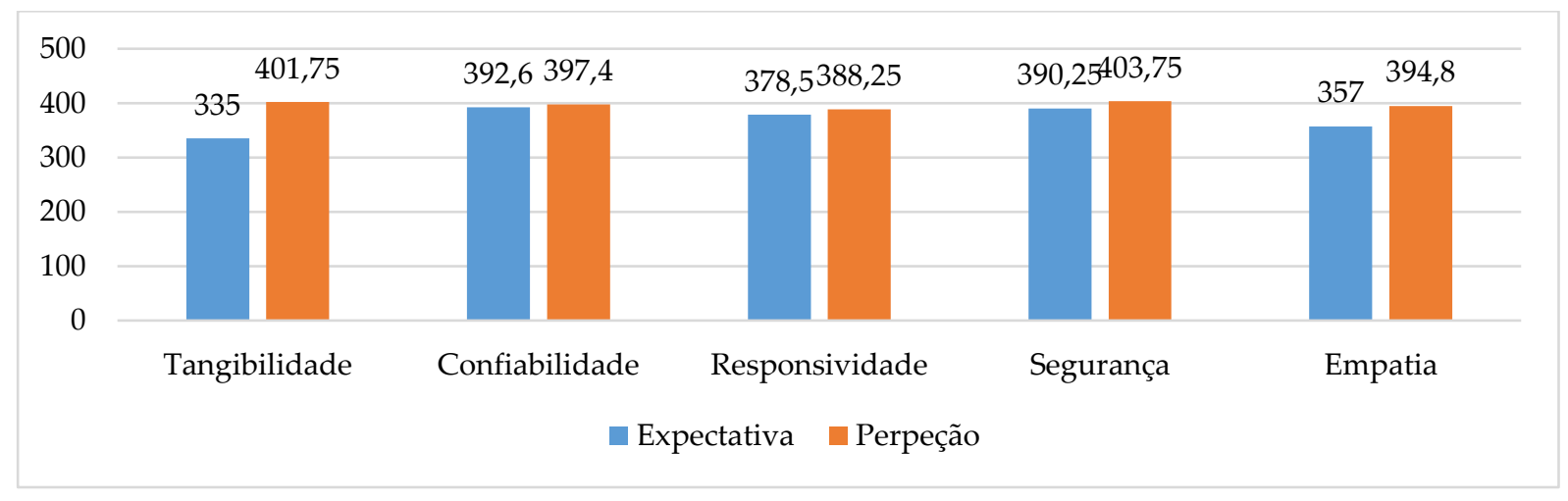

Fonte: dados da pesquisa.

Ao analisar a média das dimensões referentes às expectativas, por meio da Figura 1, observase que a dimensão que apresentou a maior média expectativa foi Confiabilidade $(392,60)$, a qual consiste na capacidade de solucionar o serviço ou problema de maneira correta dentro dos prazos combinados. 
A segunda expectativa refere-se à dimensão de Segurança $(390,25)$, que consiste no comportamento dos funcionários, transmissão de confiança, conhecimento dos funcionários para resolução de dúvidas, gentileza e cortesia.

A terceira expectativa refere-se à Responsividade (378,50), que consiste no que os clientes esperam da empresa, como serviços com rapidez e agilidade, funcionários que demonstrem disposição em ajudá-los e que não estejam muito ocupados para isso.

A quarta expectativa refere-se à Empatia (357), que envolve à atenção individualizada que a empresa oferece aos clientes, horários convenientes e os funcionários entenderem as necessidades individuais destes clientes. A quinta e última expectativa, é a Tangibilidade (335), que está relacionada às instalações físicas, equipamentos da empresa e boa aparência dos funcionários.

É possível perceber que as duas dimensões mais esperadas - Confiabilidade e Segurança, são mais características do serviço contábil. Estas dimensões se alinham ao preconizado na Estrutura Conceitual para Elaboração e Divulgação de Relatório Contábil-Financeiro (CPC 00-R1). Um dos pontos abordados pelo CPC 00 refere-se à Representação Fidedigna pelos relatórios contábeis. Segundo o CPC 00, para ser útil, a informação contábil-financeira pode apenas representar um fenômeno relevante, mas também tem que representar com fidedignidade o fenômeno que se propõe representar. Este critério se alinha, dentro da dimensão Confiabilidade, à "Registros atualizados e sem erros".

Ao analisar a média das dimensões de percepções, observa-se que a dimensão cuja maior média em relação ao desempenho percebido foi a Segurança $(403,75)$, apresentando aumento em relação às expectativas. A segunda dimensão melhor avaliada foi a Tangibilidade $(401,75)$. Confiabilidade $(397,40)$ ficou no terceiro posto de melhor avaliado. Por fim, as duas últimas dimensões foram Empatia $(394,80)$ e Responsividade $(388,25)$. Ao se analisar Dimensão, apesar de não terem mantidos os postos em relação a maior expectativa e percepção, as cinco dimensões apresentaram GAP positivo entre expectativa e percepção.

A Tabela 3 apresenta as informações referentes ao Desempenho Esperado, Desempenho Percebido e o GAP formado entre as questões: 
Tabela 3 -Desempenho Esperado, Desempenho Percebido e GAPs

\begin{tabular}{|c|c|c|c|c|c|c|c|}
\hline Dim. & Atributos & $\mathrm{DE}$ & DP & GAP & GAP-Q & GAP-D & GAP-M \\
\hline \multirow{4}{*}{ 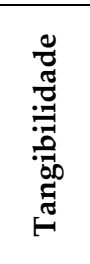 } & 1 - Equipamentos Modernos. & 370 & 378 & +8 & 0,1290 & \multirow{4}{*}{267} & \multirow{4}{*}{4,3064} \\
\hline & 2 - Instalações físicas bonitas. & 312 & 409 & +97 & 1,5645 & & \\
\hline & $\begin{array}{l}3 \text { - Vestimenta e boa aparência dos funcio- } \\
\text { nários. }\end{array}$ & 324 & 409 & +85 & 1,3709 & & \\
\hline & $\begin{array}{l}4 \text { - Aparência de acordo com o serviço ofe- } \\
\text { recido. }\end{array}$ & 334 & 411 & +77 & 1,2419 & & \\
\hline \multirow{5}{*}{$\underbrace{:}_{0}$} & 5 - Cumprimento dos prazos estabelecidos. & 363 & 392 & +29 & 0,4677 & \multirow{5}{*}{24} & \multirow{5}{*}{0,3870} \\
\hline & 6 - Interesse na resolução dos problemas. & 404 & 409 & +5 & 0,0806 & & \\
\hline & 7 - Serviços devem ser confiáveis. & 395 & 408 & +13 & 0,2096 & & \\
\hline & 8 - Cumprimento dos prazos prometidos. & 400 & 395 & -5 & $-0,0806$ & & \\
\hline & 9 - Registros atualizados e sem erros. & 401 & 383 & -18 & $-0,2903$ & & \\
\hline \multirow{4}{*}{ 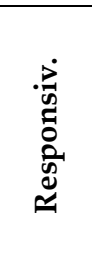 } & $\begin{array}{l}10 \text { - Precisão ao informar o início e conclu- } \\
\text { são de um serviço. }\end{array}$ & 407 & 392 & -15 & $-0,2419$ & \multirow{4}{*}{39} & \multirow{4}{*}{0,6290} \\
\hline & 11 - Atendimento imediato. & 389 & 385 & -4 & $-0,0645$ & & \\
\hline & 12 - Disposição dos funcionários em ajudar. & 397 & 411 & +14 & 0,2258 & & \\
\hline & $\begin{array}{l}13 \text { - Funcionários nunca estarão ocupados } \\
\text { para ajudar o cliente. }\end{array}$ & 321 & 365 & +44 & 0,7096 & & \\
\hline \multirow{4}{*}{ 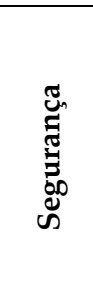 } & $\begin{array}{l}14 \text { - Confiança nos serviços prestados pelos } \\
\text { funcionários. }\end{array}$ & 396 & 407 & +11 & 0,1774 & \multirow{4}{*}{48} & \multirow{4}{*}{0,7741} \\
\hline & $\begin{array}{l}15 \text { - Segurança quanto às transações com os } \\
\text { funcionários. }\end{array}$ & 387 & 398 & +11 & 0,1774 & & \\
\hline & 16 - Gentileza por parte dos funcionários. & 397 & 416 & +13 & 0,2096 & & \\
\hline & $\begin{array}{l}17 \text { - Conhecimento dos funcionários para } \\
\text { resolução de dúvidas. }\end{array}$ & 381 & 394 & +13 & 0,2096 & & \\
\hline \multirow{5}{*}{ 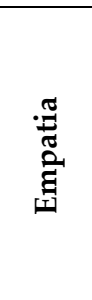 } & 18 - Atenção individualizada. & 367 & 396 & +29 & 0,4677 & \multirow{5}{*}{189} & \multirow{5}{*}{3,0483} \\
\hline & $\begin{array}{l}19 \text { - Horário de funcionamento conveniente } \\
\text { aos clientes. }\end{array}$ & 345 & 397 & +52 & 0,8387 & & \\
\hline & 20 - Atenção Personalizada. & 317 & 389 & +72 & 1,1612 & & \\
\hline & 21 - Priorização dos clientes. & 378 & 398 & +20 & 0,3225 & & \\
\hline & $\begin{array}{l}22 \text { - Funcionários compreendem as necessi- } \\
\text { dades dos clientes. }\end{array}$ & 378 & 394 & +16 & 0,2580 & & \\
\hline
\end{tabular}

Legenda: Dim: Dimensão. DE: Desempenho Esperado. DP: Desempenho Percebido. GAP-Q: Gap da Questão. GAP-D: Gap da Dimensão. GAP-M: Gap Médio.

Fonte: dados da pesquisa.

Em relação ao GAP por questão, Tabela 3, o maior foi em relação à Confiabilidade, questão n. 9 - Registros atualizados e sem erros (-18). Em segundo lugar ficou a questão relacionada à Responsividade, questão no 10 - Precisão ao informar o início e conclusão de um serviço. Em terceiro e quarto lugar ficaram as questões relacionadas com Confiabilidade - questão nํ․ 8, Cumprimento dos prazos prometidos (-5) e Responsividade - questão $n^{0} 11$ - Atendimento imediato (-4), respectivamente. As demais questões apresentaram GAPS positivos. Os gaps negativos são, justamente, de questões mais características do serviço contábil, onde se deve ter um maior zelo por parte do gestor.

Todos os GAPS por dimensão apresentaram resultados positivos. A primeira dimensão Tangibilidade - teve o maior GAP positivo e ficou com 267, isso quer dizer que foi a dimensão mais bem avaliada entre os clientes, partindo da comparação entre expectativa e percepção.

A Segunda - Confiabilidade - teve o menor GAP positivo e ficou com GAP de 24, isto não quer dizer que um resultado ruim foi obtido, mas que a dimensão teve resultados positivos, porém menores em relação às demais dimensões. 
A Terceira dimensão - Responsividade - ficou com GAP positivo de 39. A Quarta dimensão - Segurança - ficou com GAP positivo de 48. A Quinta e última dimensão - Empatia - ficou com segundo maior GAP positivo, somente atrás da Tangibilidade, com GAP positivo de 189.

Foi realizado um teste de Normalidade com os dados da pesquisa, por meio do teste Kolmogorov-Smirnov. Verificou-se que nenhuma variável apresentou distribuição normal de dados, sendo, desta forma, realizados dois testes de correlação para verificar se há relação (positiva, neutra ou negativa) entre as Expectativas e as Percepções. Os testes de correlação foram a Correlação de Spearman e Correlação de Kendall, por serem medidas de correlação não paramétricas. Os resultados são apresentados na Tabela 4:

Tabela 4 - Correlações de Spearman e Kendall para amostras pareadas

\begin{tabular}{|c|c|c|c|c|}
\hline Dimensões & $\begin{array}{c}\text { Correlação de Spe- } \\
\text { arman } \\
\end{array}$ & $\begin{array}{c}\text { Significância de } \\
\text { Spearman }\end{array}$ & $\begin{array}{c}\text { Correlação de Ken- } \\
\text { dall } \\
\end{array}$ & $\begin{array}{c}\text { Significância de } \\
\text { Kendall } \\
\end{array}$ \\
\hline ET1 - PT1 & ,493 & ,000 & $446^{* *}$ & ,000 \\
\hline ET2 - PT2 & 134 & ,300 & 119 & 285 \\
\hline ET3 - PT3 & ,332 & ,008 &, $300 * *$ & ,009 \\
\hline ET4 - PT4 & 199 & 121 & 175 & 121 \\
\hline EC5 - PC5 & 216 & ,092 & 210 & ,062 \\
\hline EC6 - PC6 &, $375^{* *}$ & ,003 & ,364 & ,003 \\
\hline EC7 - PC7 &,- 042 & 744 &,- 045 & 707 \\
\hline EC8 - PC8 &,- 093 & ,474 &,- 085 & ,467 \\
\hline EC9 - PC9 & 240 & ,061 & 223 & ,053 \\
\hline ER10- PR10 &,- 083 &, 522 &,- 075 &, 524 \\
\hline ER11- PR11 & 159 & 217 & 149 & 196 \\
\hline ER12- PR12 & 223 & ,082 & 208 & ,082 \\
\hline ER13- PR13 & $276^{*}$ & ,030 & $231^{*}$ & ,035 \\
\hline ES14- PS14 & ,090 & ,485 & ,087 & ,465 \\
\hline ES15- PS15 &, $348^{* *}$ & ,006 &, $334^{* *}$ & ,004 \\
\hline ES16- PS16 & ,288* & ,023 &, $275^{* *}$ & ,023 \\
\hline ES17- PS17 & 102 & ,429 & ,087 & ,451 \\
\hline EE18- PE18 & $284^{*}$ & ,025 & $266^{*}$ & ,018 \\
\hline EE19- PE19 & ,129 & ,317 & 122 & 273 \\
\hline EE20- PE20 & ,310* & ,014 & $255^{*}$ & ,020 \\
\hline EE21- PE21 &, $302^{*}$ & ,017 & ,292* & ,010 \\
\hline EE22- PE22 &, $340^{* *}$ & ,007 &, $317^{* *}$ & ,006 \\
\hline
\end{tabular}

Legenda: **A correlação é significativa no nível 0,01 (2 extremidades). * A correlação é significativa no nível 0,05 (2 extremidades).

Fonte: dados da pesquisa.

Por meio da Tabela 4, é possível observar as correlações de Spearman e Kendall com as respectivas significâncias das expectativas e das percepções. Verifica-se que as expectativas e as percepções estão alinhadas ou desalinhadas (desencontradas), pois quanto maior a correlação maior o alinhamento. Com base nisto, destaca-se não haver causalidade entre variáveis, mas relação entre elas.

Verifica-se, para os índices que apresentaram significância nas correlações, que as correlações apresentaram relação estatística fraca (nenhum índice superior à 0,50) e nenhum índice negativo com significância. É possível inferir que as expectativas e as percepções "caminham na mesma direção".

As variáveis que se encontram com correlação estatisticamente significativa são:

Quanto a dimensão Tangibilidade: Questão 1 (ET1-PT1) - Equipamentos Modernos e Questão 3 (ET3-PT3) - Vestimenta e boa aparência dos funcionários.

Quanto a dimensão Confiabilidade: Questão 6 (EC6-PC6) - Interesse na resolução dos problemas; 
Quanto a dimensão Responsividade: Questão 13 (ER13-PR13) - Funcionários nunca estão ocupados para ajudar o cliente.

Quanto a dimensão Segurança: Questão 15 (ES15-PS15) - Segurança quanto as transações com os funcionário e Questão 16 (ES16-PS16) - Gentileza por parte dos funcionários.

Quanto a dimensão Empatia: Questão 18 (EE18-PE18) - Atenção individualizada, Questão 20 (EE20-PE20) - Atenção Personalizada, Questão 21 (EE21-PE21) - Priorização dos clientes e Questão 22 (EE22-PE22) - Compreensão das necessidades dos clientes por parte dos funcionários.

Tabela 5 - Teste T Student para amostras pareadas

\begin{tabular}{|c|c|c|c|c|c|c|c|c|}
\hline \multirow{2}{*}{ Dimensões } & \multirow{2}{*}{ Média } & \multirow{2}{*}{$\begin{array}{l}\text { Desvio } \\
\text { Padrão }\end{array}$} & \multirow{2}{*}{$\begin{array}{l}\text { Erro Padro- } \\
\text { nizado }\end{array}$} & \multicolumn{2}{|c|}{ Int. Confiança 95\% } & \multirow{2}{*}{$\mathrm{T}$} & \multirow{2}{*}{ DF } & \multirow{2}{*}{ Sig } \\
\hline & & & & Inferior & Superior & & & \\
\hline ET1 - PT1 & $-0,3226$ & 1,4421 & 18392 &,- 40003 & 33552 &,- 175 & 61 & 861 \\
\hline${ }^{* *}$ ET2 - PT2 & $-1,4677$ & 1,75292 & 22262 & $-1,191290$ & $-1,0225$ & $-6,593$ & 61 & ,000 \\
\hline **ET3 - РT3 & $-1,2741$ & 1,85693 & 23583 & $-1,74576$ &,- 80262 & $-5,403$ & 61 & ,000 \\
\hline${ }^{* * E T 4}-\mathrm{PT} 4$ & $-1,1451$ & 1,85408 & 23547 & $-1,61601$ &,- 67431 & $-4,863$ & 61 & ,000 \\
\hline EC5 - PC5 &,- 3709 & 1,91828 & 24362 &,- 85812 & 11618 & $-1,523$ & 61 & 133 \\
\hline EC6 - PC6 & ,01613 & 1,27385 & 16178 &,- 30737 & 33963 & 100 & 61 & 921 \\
\hline EC7 - PC7 &,- 1129 & 1,68021 & 21339 &,- 53960 & 31379 &,- 529 & 61 &, 599 \\
\hline EC8 - PC8 & 1774 & 1,76044 & 22358 &,- 26965 & 62449 & 794 & 61 & ,431 \\
\hline EC9 - PC9 & ,3871 & 1,63321 & 20742 &,- 02766 & ,80185 & 1,866 & 61 & ,067 \\
\hline ER10- PR10 & 3387 & 1,87252 & 23781 &,- 13682 & ,81424 & 1,424 & 61 & 159 \\
\hline ER11- PR11 & 1612 & 1,70047 & 21596 &,- 27055 & ,59313 & ,747 & 61 & ,458 \\
\hline ER12- PR12 &,- 1290 & 1,50936 & 19169 &,- 51234 & ,25427 &,- 673 & 61 &, 503 \\
\hline **ER13- PR13 &,- 7096 & 1,33536 & 16959 & $-1,04880$ &,- 37056 & $-4,185$ & 61 & ,000 \\
\hline ES14- PS14 &,- 1774 & 1,48792 & 18897 &,- 55528 & 20044 &,- 939 & 61 & ,351 \\
\hline ES15- PS15 &,- 1774 & 1,39700 & 17742 &,- 53219 & 17735 & $-1,000$ & 61 & 321 \\
\hline ES16- PS16 &,- 3064 & 1,00145 & 12718 &,- 56077 &,- 05213 & $-2,410$ & 61 & ,019 \\
\hline ES17- PS17- &,- 2096 & 1,10345 & 14014 &,- 48990 & ,07055 & $-1,496$ & 61 & 140 \\
\hline${ }^{* *}$ EE18- PE18 &,- 4677 & 1,32712 & 16854 &,- 80477 & -,13072 & $-2,775$ & 61 & ,007 \\
\hline${ }^{* * E E 19-~ P E 19 ~}$ &,- 8387 & 1,65156 & 20975 & $-1,25813$ &,- 41929 & $-3,999$ & 61 & ,000 \\
\hline${ }^{* *}$ EE20- PE20 & $-1,1612$ & 2,01790 & ,25627 & $-1,67374$ &,- 64884 & $-4,531$ & 61 & ,000 \\
\hline${ }^{* *}$ EE21- PE21 &,- 3225 & 1,11288 & 14134 &,- 60520 &,- 03996 & $-2,282$ & 61 & ,026 \\
\hline EE22- PE22 &,- 2580 & 1,53575 & ,19504 &,- 64807 & 13194 & $-1,323$ & 61 & ,191 \\
\hline
\end{tabular}

Fonte: dados da pesquisa.

Conforme Tabela 5, tem-se os resultados das análises realizadas por meio do Teste T Pareado, tendo em vista realizar mais de uma medida em uma mesma unidade amostral ('Expectativa X Percepção' de cada respondente). Os resultados destacados com ${ }^{* *}$ e mencionados a seguir, apresentaram significância estatisticamente significativas, ou seja, existe diferença nas médias entre a expectativa e a percepção dos clientes do escritório de contabilidade.

Em relação à Tangibilidade, as questões: 2 - Instalações físicas bonitas; 3 - Vestimenta e boa aparência dos funcionários e 4 - Aparência de acordo com o serviço oferecido, existem diferenças significativas entre as expectativas e as percepções.

Em relação à Responsividade, somente a questão 13 - Disposição dos funcionários em ajudar o cliente, existe diferença significativa entre as expectativas e as percepções.

Em relação à Empatia, as questões 18 - Atenção Individualizada, 19 - Horário de funcionamento conveniente aos clientes, 20 - Atenção Personalizada e 21 - Priorização do cliente, apresentam diferenças significativas entre expectativas e percepções.

Desta forma, as questões e dimensões que apresentaram médias estatisticamente significativas, demonstram que há uma necessidade de gestão maior, a fim de reduzir esta diferença de médias. 
As dimensões Confiabilidade e Segurança não apresentaram relação estatisticamente significativa. Para as demais variáveis de análise, não foram identificadas diferenças estatisticamente significativas entre a expectativa e a percepção. É possível inferir que não há diferenças estatísticas entre o que os clientes desejam e esperam da organização com o que se foi apresentado pela mesma.

Como visto anteriormente, apesar da maioria dos GAPS - diferença entre desempenho esperado e desempenho percebido, apresentarem resultados positivos, 4 deles apresentaram resultados negativos, ou seja, precisam ser analisados mais atentamente pelo gestor do escritório.

Para melhoria em relação às questões que apresentaram GAPs estatisticamente diferentes, com valores negativos, são apresentadas algumas sugestões, conforme Quadro 1:

Quadro 1 - Sugestões de melhorias para a empresa

\begin{tabular}{|c|c|l|}
\hline Dimensão & Variável & \multicolumn{1}{c|}{ Sugestões } \\
\hline Confiabilidade & $\begin{array}{c}\text { Cumprimento } \\
\text { dos prazos acer- } \\
\text { tados. }\end{array}$ & $\begin{array}{l}\text { - Redistribuição do serviço, em que cada funcionário deve ser responsável } \\
\text { por um número X de empresas, de acordo com sua experiência profissio- } \\
\text { nal; } \\
\text { - Possível contratação de pessoal para evitar sobrecarga de trabalho. }\end{array}$ \\
\hline Confiabilidade & $\begin{array}{c}\text { Registros atuali- } \\
\text { zados e sem er- } \\
\text { ros. }\end{array}$ & $\begin{array}{l}\text { - Conferência do serviço por parte de um terceiro; } \\
\text { - Conferência do serviço por parte de um responsável de setor - visto que } \\
\text { náo ham encarregado no setor de Contabilidade; } \\
\text { - Investimento em cursos específicos para cada área, tendo em vista que a } \\
\text { legislação sempre está mudando, de acordo com cada necessidade do pro- } \\
\text { fissional que execute o serviço. }\end{array}$ \\
\hline Responsividade & $\begin{array}{c}\text { Precisão ao in- } \\
\text { formar início e } \\
\text { conclusão de um } \\
\text { serviço }\end{array}$ & $\begin{array}{l}\text { - Treinamento de pessoal no quesito "atendimento ao cliente": por meio de } \\
\text { dinâmicas, sempre mostrando como o cliente gostaria de ser tratado. }\end{array}$ \\
\hline Responsividade & $\begin{array}{c}\text { Atendimento } \\
\text { imediato. }\end{array}$ & - Treinamento de pessoal no quesito "atendimento ao cliente"; \\
- Contratação de pessoal.
\end{tabular}

Fonte: Elaborado pelos autores.

Considerando os "GAPS" negativos foram criadas sugestões de melhoria para que a Empresa busque aumentar o grau de satisfação dos clientes e possa ser mais competitiva no mercado.

\section{CONSIDERAÇÕES FINAIS}

A necessidade de satisfação do cliente em relação à qualidade do serviço oferecido pelos escritórios de contabilidade e a superação do que é percebido com relação ao esperado podem ser um ponto chave da intenção comportamental e da fidelidade do cliente, diminuindo assim a pressão exercida pela concorrência. Desta forma, o objetivo desta pesquisa foi avaliar a qualidade percebida pelo serviço prestado em um escritório contábil, localizado em Foz do Iguaçu PR, por meio da aplicação da escala Servqual.

Por meio da aplicação de questionário, foram identificados o nível esperado e o nível percebido de qualidade nas dimensões elencadas na escala Servqual. Observou-se que as médias gerais para as dimensões foram positivas, apesar de algumas das variáveis apresentarem GAPs negativos. A avaliação da qualidade dos serviços prestados pelo escritório de contabilidade, por se tratar de um serviço importante para as empresas, evidenciou que as duas maiores dimensões esperadas pelos clientes foram Confiabilidade e Segurança.

Junto à maior expetativa, a dimensão Segurança apresentou maior percepção pelos clientes, ao lado da dimensão Tangibilidade. No entanto, esta última, apresentou um dos menores valores esperados, podendo ser perceptível um elevado valor no GAP positivo. 
Apesar de todos os GAP's, por dimensão, obterem resultados positivos, a análise apontou que 4 questões obtiveram GAP negativo e precisam ser melhoradas dentro da empresa, sendo estes: Cumprimento dos prazos prometidos, Registros atualizados e sem erros, Precisão ao informar o início e conclusão de um serviço e Atendimento imediato.

Para recomendações de trabalhos futuros, sugere-se estudos da Escala Servqual aplicados a percepção da qualidade nas entidades de classe contábil, nas entidades em que os contadores apresentam relação e nos serviços públicos em que os contadores buscam atendimento. Por fim, outros estudos de qualidade de serviço prestado em escritórios de contabilidade, utilizando-se de outras escalas para comparações, a fim de evidenciar quais outras dimensões devem ser levadas em consideração neste ramo.

\section{REFERÊNCIAS}

Albrecht, K., \& Bradford, L. J. (1992). Serviços com qualidade: a vantagem competitiva. In Serviços com qualidade: a vantagem competitiva. Makron.

Associação Brasileira De Normas Técnicas. (2000). NBR ISO 9004: sistemas de gestão da qualidade-diretrizes para melhorias de desempenho. ABNT.

Augusto, H. C. G. (2006). Os serviços contábeis necessários à gestão das empresas do comércio varejista da cidade de Sousa-PB. Monografia Curso Especialização em Gestão de Negócios Público e Gestão estratégica de negócios-Centro de Ciências Jurídicas e Sociais, Universidade Federal de Campina Grande, Campus de Sousa/PB.

Caon, M., \& Corrêa, H. L. (2002). Gestão de serviços. Editora Atlas SA.

Carvalho, J. R. M., \& Tomaz, F. A. S. (2010). Qualidade em serviços contábeis: um estudo nas empresas do setor de comércio varejista de material de construção. Revista Alcance, 17(2), 192-204.

Chang, Y. H., \& Yeh, C. H. (2017). Corporate social responsibility and customer loyalty in intercity bus services. Transport Policy, 59, 38-45.

Comitê de Pronunciamentos Contábeis (CPC). (2011). CPC 00 (R1) - Estrutura Conceitual para Elaboração e Divulgação de Relatório Contábil-Financeiro. Recuperado em 09 novembro de 2017 de: http://www.cpc.org.br/CPC/DocumentosEmitidos/Pronunciamentos/Pronunciamento?Id=80.

Dancey, C. P., \& Reidy, J. (2006). Estatística sem matemática para psicologia. Penso Editora.

Evans, J. R., \& Lindsay, W. M (2000). Administración y control de la calidad. (6ª ed.). México: Thomson.

Fadel, M. A. V., \& Regis Filho, G. I. (2009). Percepção da qualidade em serviços públicos de saúde: um estudo de caso. Revista de Administração Pública-RAP, 43(1), 07-22. 
Faião, A. M. P., Maranhão, R. F. A., \& Torres, R. G. (2013). Percepção dos colaboradores internos da prestação de serviços em restaurantes institucionais. Revista Hospitalidade, 10(2), 422-443.

Field, A. (2009). Descobrindo a estatística usando o SPSS-2. Bookman Editora.

Fitzsimmons, J. A., \& Fitzsimmons, M. J. (2000). Administração de Serviços-: Operações, Estratégia e Tecnologia da Informação. AMGH Editora.

Fragoso, J. T., \& Espinoza, I. L. (2017). Assessment of banking service quality perception using the SERVPERF model. Contaduría y Administración, 62(4), 1294-1316.

Grönroos, C. (1995). Relationship marketing: the strategy continuum. Journal of the Academy of Marketing Science, 23(4), 252-254.

IBGE - Instituto Brasileiro de Geografia e estatística. PAS - Pesquisa Anual de Serviços, 2016. Recuperado em 09 novembro de 2017 de: http://www.ibge.gov.br/home/estatistica/economia/

Izogo, E. E., \& Ogba, I. E. (2015). Service quality, customer satisfaction and loyalty in automobile repair services sector. International Journal of Quality \& Reliability Management, 32(3), 250-269.

Jeremias Junior, J., \& Martins, V. A. (2017). Perfis de Valores Organizacionais: Uma Análise das 50 Maiores Empresas Privadas Brasileiras. Caderno Profissional de Administração da UNIMEP, 7(1), 101-117.

Johnston, D. M. (1995) Mensuração da qualidade de serviços através da escala Servqual: sua operacionalização no setor de serviços bancários business-to-business. 120 f. Dissertação (Mestrado em Administração)-Programa de Pós-Graduação em Administração, Universidade Federal do Rio Grande do Sul, Porto Alegre.

Las Casas, A. L. (1994). Qualidade total em serviços: conceitos, exercícios, casos práticos. São Paulo. Editora Atlas.

Lee, L. T., Peng, C. S., \& Fan, C. K. (2016). An empirical study of service quality: web service business transformation. International Journal of Computational Science and Engineering, 12(1), 58-64.

Lopes, A. B., \& Martins, E. (2007). Teoria da contabilidade: uma nova abordagem. São Paulo. Editora Atlas.

Madruga, S. R., Colossi, N., \& Biazus, C. A. (2016). Funções e Competências Gerenciais do Contador . Revista de Administração da UFSM, 9(2), 182-191.

Martins, P. G.; Laugeni, F. P. (2001). Administração da Produção. São Paulo: Editora Saraiva 
Martins, V. A. (2015). Proposta de um mapa estratégico para uma universidade pública. Revista Evidenciação Contábil \& Finanças, 3(2), 88-103.

Mochon, F., \& Troster, R. L. (1994). Introdução à economia. São Paulo: Makron.

Parasuraman, A., Zeithaml, V. A., \& Berry, L. L. (1985). A Conceptual Model of Service Quality and its Implications for Future Research. Journal of Marketing, 49, 41-50.

Parasuraman, A., Zeithaml, V. A., \& Berry, L. L. (1988). Servqual: A multiple-item scale for measuring consumer perc. Journal of retailing, $64(1), 12-40$.

Pradela, A. (2015). Quality of Graduates' Preparation for Labour Market-A ServQual Analysis. Procedia-Social and Behavioral Sciences, 174, 1671-1677.

Rosa, M. M., Petri, S. M., Petri, L. R. F., \& Casagrande, M. D. H. (2014). O Balanced Scorecard como ferramenta de gestão estratégica e orçamentária da Fundação Cultural de Florianópolis. Revista Evidenciação Contábil \& Finanças, 2(1), 39-58.

Slack, N .et al, (2002) Administração da produção. 2 ed. São Paulo: Editora Atlas

Souza, A; Walter, S. A.; Bach, T. M. (2013) Avaliação da qualidade dos serviços: Um estudo de caso em uma empresa de telecomunicações do Vale do Itajaí, Blumenau, Anais do XVI Simpósio de Administração da Produção, Logística e Operações Internacionais. São Paulo, Brasil.

Souza, N. A. P. (2010). Qualidade no atendimento dos serviços de hotelaria em Ribeirão Preto: diferenças entre turistas de negócios e lazer. Tese (Doutorado em Administração)-Programa de Pós-Graduação em Administração, Universidade de São Paulo, Ribeirão Preto, São Paulo, Brasil.

Tan, K. C., \& Pawitra, T. A. (2001). Integrating SERVQUAL and Kano's model into QFD for service excellence development. Managing Service Quality: An International Journal, 11(6), 418-430.

Téboul, J. (1999). A era dos serviços: uma nova abordagem de gerenciamento. Editora Qualitymark.

Thomé, I. (2001). Empresas de serviços contábeis: estrutura e funcionamento. Editora Atlas SA.

Wolniak, R., \& Skotnicka-Zasadzien, B. (2012). The concept study of Servqual method's gap. Quality \& Quantity, 46(4), 1239-1247.

Yousapronpaiboon, K. (2014). SERVQUAL: Measuring higher education service quality in Thailand. Procedia-Social and Behavioral Sciences, 116, 1088-1095.

Wilson, A., Zeithaml, V. A., Bitner, M. J., \& Gremler, D. D. (2012). Services marketing: Integrating customer focus across the firm. McGraw Hill. 
Zeithaml, V. A., Parasuraman, A., \& Berry, L. L. (1990). Delivering quality service: Balancing customer perceptions and expectations. Simon and Schuster. 